
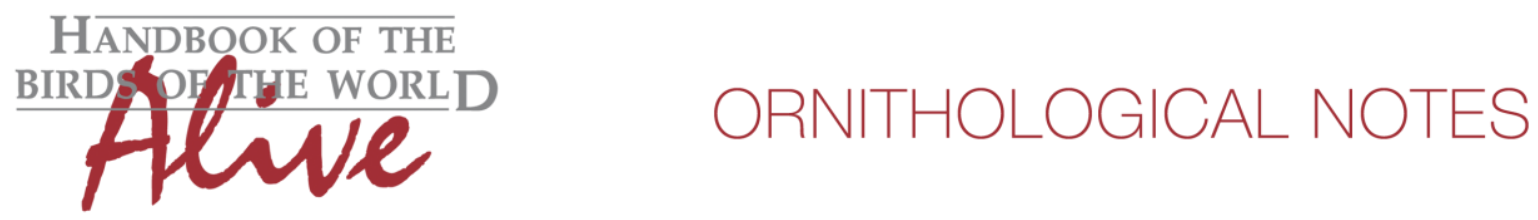

\title{
Notes on the vocalizations of Olive-crowned Crescentchest (Melanopareia maximiliani)
}

Peter Boesman

In the following we briefly analyze and compare voice of the different races of Olive-crowned Crescentchest (Melanopareia maximiliani). We also try to quantify the extent of any vocal differences using the criteria proposed by Tobias et al. (2010), as a support for taxonomic review. We have made use of sound recordings available on-line from Xeno Canto (XC) and Macaulay Library (ML).

HBW indicates a clear difference in song pace between races maximiliani/argentina and pallida, the latter being much faster (Krabbe et al. 2003). It would seem that this is in fact only partially correct.

There are indeed two distinct groups with a differently paced song (Fig. 1).

The slow paced song is heard from maximiliani, argentina and most birds from the race pallida. More specifically, all birds from Paraguay (ML195428, ML57882), N Argentina (XC54064, XC54065 from Formosa and ML83851 from Chaco) south to E Cordoba (own recordings from Miramar XC272983/4).

The fast song is only heard from birds $\mathrm{N}$ and $\mathrm{W}$ of Cordoba (the salinas and foothills of the endemic center $\mathrm{W}$ of Cordoba).

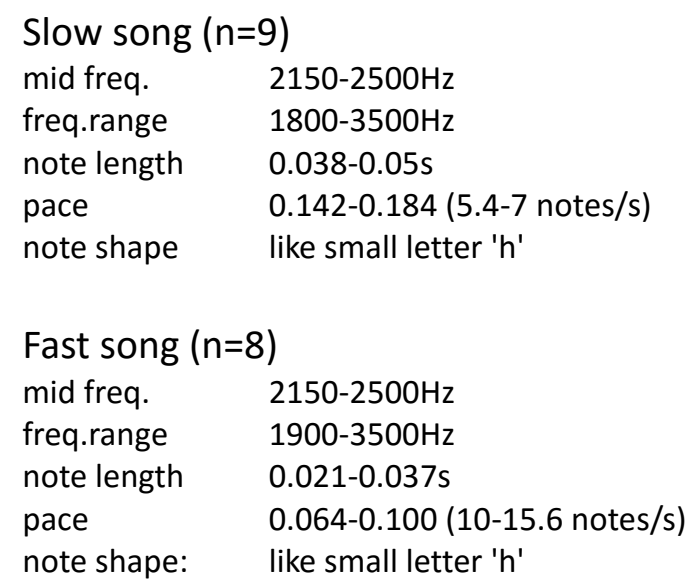

There is a clear difference in note length (score 1-2) and pace (score 3).

Furthermore, the fast song usually gradually rises in frequency at start, and often ends with a short lower-pitched note, while the slow song typically has notes at about the same frequency (but occasionally also rises at first). 


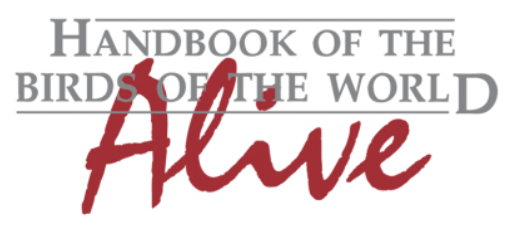

\section{ORNITHOLOGICAL NOTES}
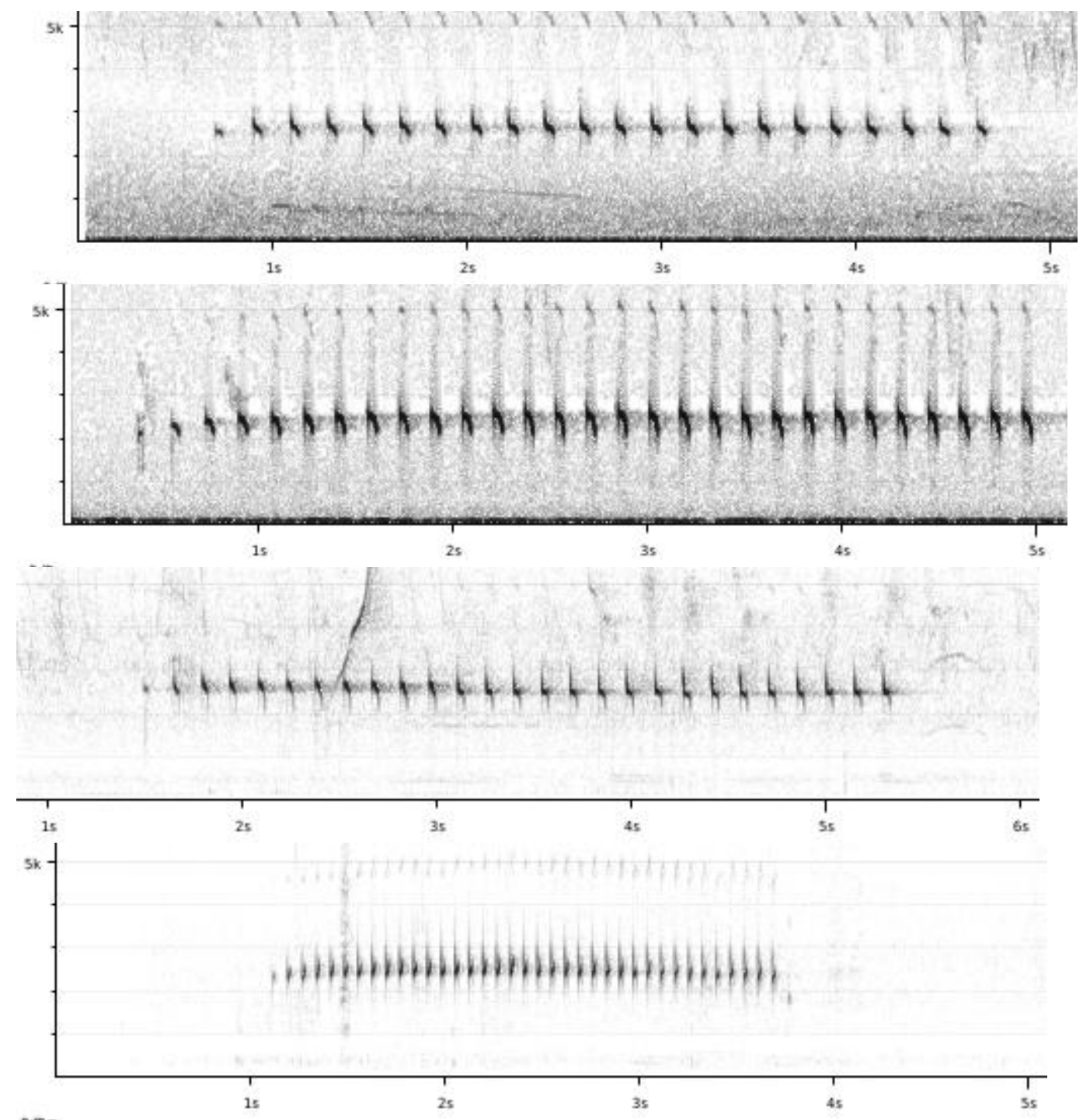

Figure 1: From top to bottom: typical song of races maximiliani, argentina, pallida (Miramar area), pallida (Cordoba area)

If note length and pace are considered independent variables, then the total score for vocal difference would be about 4 .

The vocal difference however doesn't follow the present taxonomic division. This suggests that there is actually an undescribed taxon in the south parapatric to pallida (Fig. 2). This would not be really surprising given that the Cordoba region is known as an endemic center, but unlike many other endemic taxa, these birds actually occur at lower elevation, which is really surprising. 

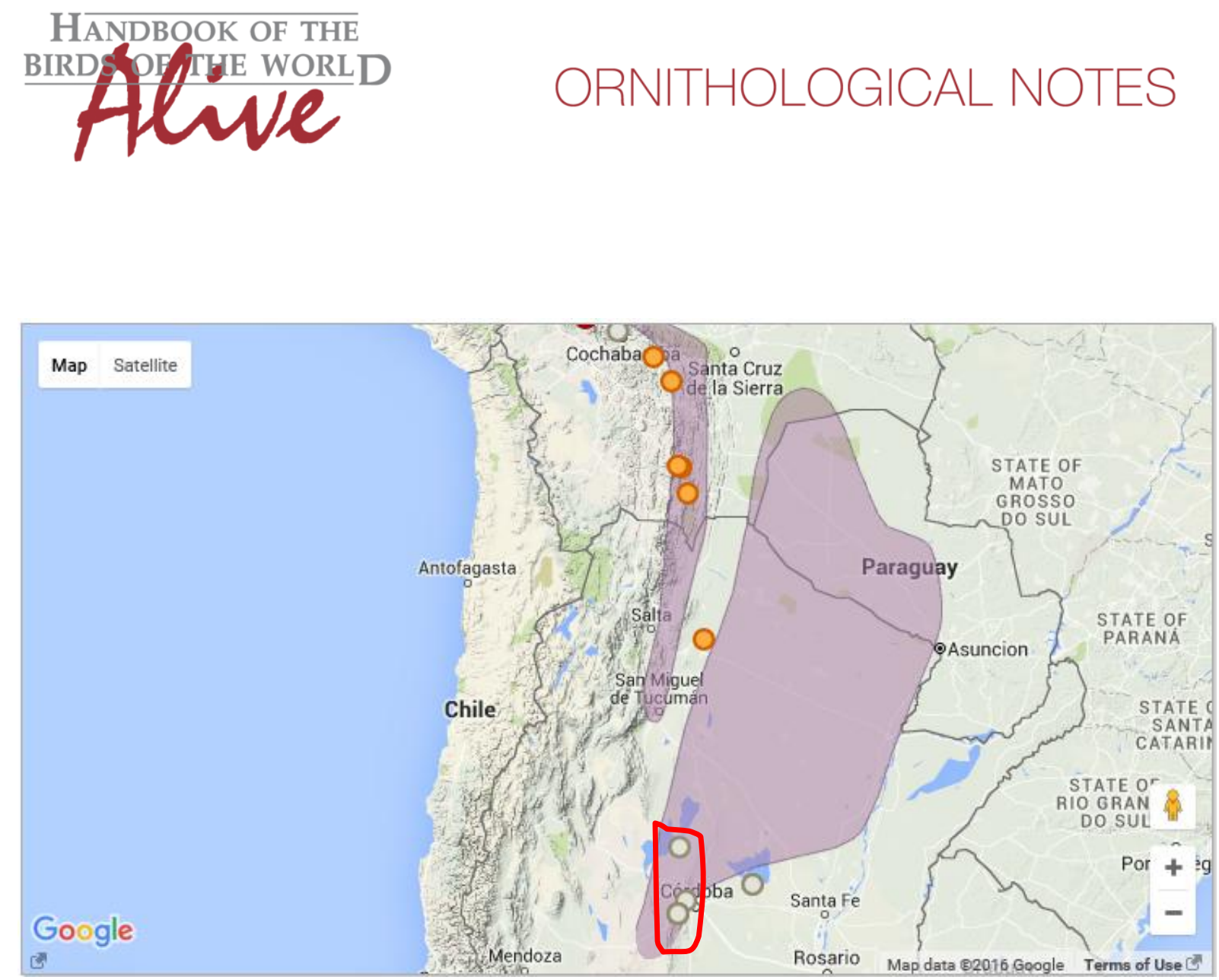

Figure 2: The encircled region shows where 'fast song has been recorded

This note was finalized on 10th June 2015 , using sound recordings available on-line at that moment. We would like to thank in particular the sound recordists who placed their recordings for this species on XC and ML: Juan Areta, Nick Athanas, Peter Boesman, Miguel Castelino, Carlos Ferrari, Rosendo Fraga, Dan Lane, Bernabe Lopez-Lanus, Niels Krabbe, Sjoerd Mayer,.

\section{References}

Krabbe, N.K. \& Schulenberg, T.S. (2003). Olive-crowned Crescentchest (Melanopareia maximiliani). In: del Hoyo, J., Elliott, A., Christie, D.A. (eds.). Handbook of the Birds of the World Vol. 8. Lynx Edicions, Barcelona.

Tobias, J.A., Seddon, N., Spottiswoode, C.N., Pilgrim, J.D., Fishpool, L.D.C. \& Collar, N.J. (2010). Quantitative criteria for species delimitation. Ibis 152(4): 724-746.

\section{Recommended citation}

Boesman, P. (2016). Notes on the vocalizations of Olive-crowned Crescentchest (Melanopareia maximiliani). HBW Alive Ornithological Note 67. In: Handbook of the Birds of the World Alive. Lynx Edicions, Barcelona. (retrieved from http://www.hbw.com/node/931951 on 15 May 2016). 